\title{
O FORTALECIMENTO DA IDENTIDADE CAMPONESA: REPERCUSSÕES DO PROGRAMA NACIONAL DE EDUCAÇÃO NA REFORMA AGRÁRIA NOS ESTADOS DO CEARÁ, MINAS GERAIS E PARANÁ (1998-2011)*
}

\author{
Gema Galgani Silveira Leite Esmeraldo ${ }^{1}$ \\ Mônica Castagna Molina ${ }^{2}$ \\ Maria Isabel Antunes-Rocha ${ }^{3}$
}

\begin{abstract}
RESUMO: O artigo discutiu os resultados da II Pesquisa sobre o Programa Nacional de Educação na Reforma Agrária (PRONERA), em sua fase qualitativa, focalizando as repercussóes de seus cursos na trajetória de egressos residentes em nove assentamentos localizados nos Estados do Ceará, Minas Gerais e Paraná. Foram realizadas entrevistas narrativas junto a egressos dos três estados sendo problematizadas à luz do método analítico do materialismo dialético. Observaram-se repercussões nas dimensóes pessoal (ampliação dos níveis de escolaridade e de atuação socioprofissional) e coletiva (escola mais próxima da realidade camponesa e do setor produtivo) e possibilidades de compreensão de identidade camponesa que sinaliza para resistências e lutas nos territórios de produção e reprodução de vida.
\end{abstract}

Palavras-chave: PRONERA. Identidade campesina socioterritorial. Reforma agrária.

\section{THE STRENGTHENING OF PEASANT IDENTITY: REPERCUSSIONS OF The National Program of Education in Agrarian Reform in The States of Ceará, Minas Gerais, ANd Paraná (1998-2011)}

ABSTRACT: This article addresses the results of the Second Survey on the National Program of Education in Agrarian Reform (PRONERA) in its qualitative phase, focusing on the repercussions of courses offered on the trajectory of former residents in nine settlements of the States of Ceará, Minas Gerais, and Paraná. Narrative interviews were carried

\footnotetext{
*Artigo resultado da análise das pesquisas realizadas em três estados (Ceará, Minas Gerais e Paraná) inseridas na II Pesquisa Nacional sobre Educação na Reforma Agrária, sendo financiada pelo Instituto Nacional de Colonização e Reforma Agrária, pelo Ministério de Desenvolvimento Agrário (MDA) e pelo Instituto de Pesquisa Econômica Aplicada.

${ }^{1}$ Universidade Federal do Ceará - Fortaleza (CE), Brasil. E-mail: gemaesmeraldo@gmail.com

${ }^{2}$ Universidade de Brasília - Planaltina (DF), Brasil. E-mail: mcastagnamolina@gmail.com

${ }^{3}$ Universidade Federal de Minas Gerais - Belo Horizonte (MG), Brasil.

E-mail: isabelantunes.rocha@gmail.com

DOI: 10.1590/ES0101-73302017180449
} 
out with graduates of all three states, with questionings in the light of dialectical materialism method of analysis. There were repercussions on personal (expansion of educational levels and socio-professional activity) and collective dimensions (school closer to peasant reality and productive sector), as well as possibilities of understanding the peasant identity, which signals to resistance and struggles in territories of life production and reproduction.

Keywords: PRONERA. Socio-territorial peasant identity. Agrarian reform.

\section{LE RENFORCEMENT DE L'IDENTITÉ PAYSANNE: LES RÉPERCUSSIONS DU Programme National d'ÉdUCATION EN RÉforme AGRAIRE dans les états du CEará, Minas Gerais et Paraná (1998-2011)}

RESSMÉ: L'article porte sur les résultats de la deuxième recherche sur le Programme National d'Éducation à la Réforme Agraire (PRONERA), dans sa phase qualitative, en mettant l'accent sur les répercussions des cours offris dans la trajectoire des diplômés résidant dans neuf colonies situées dans les états du Ceará, Minas Gerais et Paraná. Interviews narratives ont été réalisées auprès des diplômés de trois états avec des questionnements à la lumière de la méthode d'analyse du matérialisme dialectique. On a observé l'impact sur les dimensions personnelles (expansion des niveaux d'éducation et activités socio-professionnelles) et collective (école plus proche de la réalité paysanne et du secteur productif), ainsi que les possibilités de compréhension de l'identité paysanne, qui indiquent les résistances et les luttes dans les territoires de production et reproduction de la vie.

Mots-clés: PRONERA. Identité paysanne socioterritoriale. La réforme agraire.

\section{Introdução}

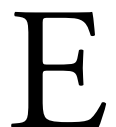

ste trabalho discute as repercussóes nas trajetórias pessoais e sociopolíticas de egressos dos cursos ofertados pelo Programa Nacional de Educação na Reforma Agrária (PRONERA), entre 1998 e 2011, nos estados do Ceará, Minas Gerais e Paraná, focalizando os aspectos relacionados à construção identitária de jovens e adultos assentados. Os dados aqui apresentados integram, parcialmente, o conjunto das informaçóes produzidas pela II Pesquisa Nacional sobre a Educação na Reforma Agrária (II PNERA) desenvolvida pelo Instituto de Pesquisa Econômica Aplicada (IPEA), no período de 1998 a 2011. A II PNERA foi realizada em duas fases: quantitativa e qualitativa. Na primeira, de natureza censitária, foram produzidas informações sobre a dimensão alcançada pelas ações do Programa (IPEA, 2015). A segunda foi desenvolvida em sete estados ${ }^{1}$, 
contemplando as repercussôes no âmbito das trajetórias dos egressos, nos assentamentos, nas escolas, nos movimentos sociais e sindicais e nas instituiçóes públicas envolvidas com o Programa.

Os resultados da pesquisa quantitativa indicaram que, nesse período, foram ofertados 320 cursos em diferentes modalidades de ensino, com registro de 164.894 ingressantes, alcançando todas as regiōes brasileiras (IPEA, 2015, p. 9). $\mathrm{Na}$ fase qualitativa observou-se que houve:

- melhoria no padrão de vida dos egressos;

- maior envolvimento da prática escolar com a realidade campesina;

- ampliação das expectativas e de interesse dos assentados com relação aos estudos;

- adoção de práticas agroecológicas por parte de egressos dos cursos; e

- criaçáo de núcleos de pesquisa em universidades com consequente ampliação da produção acadêmica sobre o tema (IPEA, 2016a; 2016b; 2016c; 2016d; 2016e; 2016f; 2016g; 2016h).

Nessa perspectiva considerou-se como relevante apresentar uma parte desses resultados neste artigo. Para a discussão aqui proposta foram selecionados aspectos que dizem respeito às repercussóes na trajetória pessoal e sociopolítica dos egressos tendo em vista que estas foram as dimensóes que apresentaram maior correlação nos resultados apresentados pelos Estados que participaram da pesquisa qualitativa. A seleção dos Estados do Ceará, Minas Gerais e Paraná fundamentou-se no fato de que os mesmos desenvolveram cursos em todas as modalidades e níveis de ensino, e também construíram cursos específicos que foram o foco das pesquisas. Neste texto dar-se-á destaque a esses cursos.

No Estado do Ceará, ressaltou-se a experiência pioneira do Programa Residência Agrária (PRA), projeto que vinculou formaçáo inicial e continuada para estudantes dos cursos de graduação e de pós-graduação em Ciências Agrárias voltados para a atuação em programas de Assistência Técnica e Extensão Rural (ATER) e Assistência Técnica e Social (ATES). Em Minas Gerais, o destaque foi dado à formação de educadores, com criação de cursos de Licenciatura em Educação do Campo. No Paraná, enfatizou-se a formação técnica, referenciada na agroecologia, que estimulou a implantação de práticas produtivas sustentáveis na maioria dos assentamentos onde residiam os egressos (IPEA, 2016d; 2016e; 2016g).

O texto trabalhou com a orientação do método analítico (o materialismo dialético) entendendo-o como um processo teórico-metodológico que considera as relaçôes sociais como fenômenos sociais totais, os quais requerem o diálogo entre as dimensões econômicas e políticas. Assim é que o método se faz interpre- 
tativo ao trazer à tona as contradiçóes que as estruturas econômicas de base capitalista produzem para dominar pessoas, relaçóes, natureza etc. Para Ianni (1987, p. 8), "o princípio da contradição governa o modo de pensar e o modo de ser", sendo, portanto, produtor de condiçóes estruturantes de qualquer sociedade e por isso deve ser colocado em posição de crítica permanente.

Com essa orientação procurou-se compreender e captar os reflexos, os ecos, as influências das açóes desencadeadas nos processos formativos dos camponeses colocados em curso por essa política pública que tem a educação como o desencadeador de formação humana. Buscou também identificar e analisar em que medida os cursos, nos diferentes níveis de escolaridade e de áreas de conhecimento, foram capazes de fazer sentir os reflexos da sua ação na vida pessoal, familiar, associativa e no contexto social mais amplo de atuação dos educandos egressos dos cursos apoiados pelo PRONERA, bem como nas suas práticas educativas desenvolvidas nas escolas de educação básica das áreas de Reforma Agrária nas quais esses atuavam (no caso dos cursos de magistério, pedagogia da terra e das licenciaturas). Ressaltando que o objetivo da análise proposta para este artigo não foi comparar, mas, sim, focalizar três experiências diferenciadas em termos de oferta de cursos demandados por movimentos sociais e realizar o diálogo crítico em torno de seus resultados.

Em cada Estado foram selecionados três assentamentos, considerando a quantidade e a diversidade de cursos desenvolvidos. Os dados tratados neste artigo foram extraídos das entrevistas narrativas que abordaram a trajetória de vida do egresso antes, durante e depois de sua participação como aluno nos cursos ofertados pelo PRONERA. Outros instrumentos metodológicos foram trabalhados na pesquisa, mas seus dados não são objeto de análise neste artigo. No Ceará foram realizadas nove entrevistas nos Assentamentos Santana, Lagoa do Mineiro e 25 de Maio (três em cada assentamento) contemplando cinco mulheres e quatro homens. Em Minas Gerais foram obtidas nove entrevistas nos Assentamentos Primeiro de Junho, Oziel Alves Pereira e Nova Nazaré com quatro homens e cinco mulheres. No Paraná realizou-se a pesquisa nos Assentamentos de Ireno Alves dos Santos, Marcos Freire e 8 de Junho e foram realizadas nove entrevistas com cinco homens e quatro mulheres. As entrevistas narrativas foram obtidas nos próprios assentamentos de origem e/ou de trabalho dos egressos e sua seleção se deu a partir da análise de sua maior participaçáo nos cursos ofertados pelo PRONERA, para garantir uma seleção daqueles que construíram sua formação escolar desde o ensino inicial até a realização de curso superior em modalidades oferecidas pelo programa. As especificidades de cursos de graduação foram levadas em conta para a seleção em cada Estado, a fim de permitir a análise dos cursos especiais ofertados nos Estados. Também foi considerado o recorte de gênero em cada ente federado.

Para organizar a discussão, este artigo está estruturado em tópicos. O primeiro apresenta uma visão geral do PRONERA e das açóes desenvolvidas 
em cada um dos Estados pesquisados. O segundo analisa as repercussôes a partir das entrevistas narrativas, a terceira parte traz reflexóes problematizadoras sobre as contradiçóes relacionadas às relaçōes entre o projeto de construção da identidade camponesa encontrada nas entrevistas com o modelo de campo e de sociedade historicamente implantado no Brasil. Por fim a título de consideraçóes finais, o quarto tópico trata da reflexão sobre as contradições do Programa como elementos de inovação e transformação.

\section{Sobre o PRONERA e as ações nos Estados do Ceará, Minas Gerais e Paraná}

A negação de direitos aos povos do campo, historicamente recorrente no Brasil, foi o principal elemento mobilizador das lutas empreendidas pelos movimentos sociais e sindicais do campo, que lutavam por terra. Em meados da década de 1990, aliaram-se para construir o Movimento por uma Educação do Campo, com a compreensão de que o modelo da educação rural não atendia ao projeto de fortalecimento do modo de vida camponês. Havia projetos em disputa seja para desencadear a luta por terra, seja para garantir educação para as populaçôes assentadas. A crítica se fazia por outra base pedagógica que considerasse o modo de vida, de produção e reprodução que resguardasse os modos de ser e estar em condição de existência camponesa. O movimento configurou-se então como um conjunto estruturado de princípios, conceitos e práticas, que trazia um sentido profundo de crítica ao capitalismo, desde sua perspectiva espoliadora ao trabalho autônomo e referenciado na liberdade e no domínio dos meios de produção, até a captura das sociabilidades que sustentavam comunidades tradicionais. $\mathrm{O}$ movimento partia, assim, da materialidade vivida pelos camponeses para expressar suas contradiçôes e por ela anunciar outros projetos em disputa. A educação que se apresentou é herdeira dos movimentos de Educação Popular e passou a se denominar Educação do Campo.

O PRONERA foi instituído em 16 de abril de 1998, por meio da Portaria no 10/1998, do então Ministério Extraordinário da Política Fundiária, como uma das primeiras conquistas do Movimento por uma Educação do Campo, visando promover açóes de educaçáo junto aos assentados da Reforma Agrária. Esse movimento foi empreendido por movimentos sociais e sindicais por meio de um conjunto de lutas e propostas visando garantir o direito à educação. Segundo Molina (2004, p. 61), "o PRONERA e a Educação do Campo fazem parte do mesmo tempo histórico". A partir de sua criação o programa foi sendo executado em articulação interinstitucional, que envolvia ministérios, órgãos estaduais, universidades, movimentos sociais, sindicais e organizaçóes náo governamentais.

O programa começou com a modalidade alfabetização de jovens e adultos; depois, evoluiu para oferta dos anos iniciais e finais do Ensino Fundamental 
e Ensino Médio profissionalizante; na sequência incorporou demandas da oferta dos egressos dos cursos médios e técnicos por Educação Superior e Pós-graduação.

As açóes do PRONERA, no Estado do Ceará, contemplaram a implantação de 12 cursos, sendo 8 de Ensino Fundamental, 2 de Ensino Médio e 2 de Educação Superior, atendendo um total de 4.395 concluintes $(4.163 \mathrm{em}$ alfabetização e Ensino Fundamental, 106 em Ensino Médio e 126 em Educação Superior). A ação denominada PRA surgiu, em 2004, com a intenção de ampliar o campo de formação de profissionais e estudantes das ciências agrárias para atuarem em políticas de ATER e ATES. Ofereceu aos estudantes de graduação Estágios de Vivência nas áreas de assentamentos rurais que atingia, a cada ano, cerca de 15 a 20 estudantes e ofereceu um Curso de Especialização em Agricultura Familiar e Camponesa e Educação do Campo para 35 egressos de cursos de graduação, filhos de assentados e técnicos de ATER/ATES (ESMERALDO et al., 2009, p. 63).

Em Minas Gerais, o programa apoiou a implantação de 25 cursos, sendo 17 de alfabetização, anos iniciais e finais do Ensino Fundamental, 6 de Educação Superior, 1 de nível técnico e 1 de especialização, contemplando um total de 6.420 concluintes (6.310 em alfabetizaçáo e Ensino Fundamental, 18 no Ensino Médio e 92 na Educação Superior e especialização). Vale ressaltar que a oferta do Curso de Licenciatura em Educação do Campo, entre 2004 e 2010, se constituiu em modelo para a criação do Programa de Apoio à Formaçáo Superior em Licenciatura em Educação do Campo (PROCAMPO), criado pelo Ministério da Educação (MEC), em 2007, que agora é desenvolvido em 43 universidades brasileiras (ANTUNES-ROCHA; MOLINA, 2014, p. 240).

No Paraná, o PRONERA implantou 17 cursos (alfabetização de jovens e adultos, especialização em Educação do Campo e agricultura familiar, graduação em Pedagogia e técnico em nível médio de Agroecologia) com um total de 1.085 concluintes. Nos cursos de alfabetização e educação fundamental formou 611 estudantes, 260 no Ensino Médio e 21 na Educação Superior. Vale ressaltar que foram desenvolvidos dez cursos de nível médio com ênfase em Agroecologia.

Os três Estados ofertaram 54 cursos com um total de 11.900 egressos em diferentes níveis e modalidades.

\section{Educação como ato de transformação: direito de acesso e ampliação das oportunidades profissionais}

A partir dos dados obtidos na pesquisa junto aos três Estados (Ceará, Minas Gerais e Paraná), foi possível observar repercussóes na trajetória pessoal e sociopolítica dos egressos. Em termos pessoais, identificou-se a ampliação dos níveis de escolaridade e de maior oportunidade de inserçáo socioprofissional. Na tra- 
jetória sociopolítica, perceberam-se repercussóes positivas na atuação dos egressos na escola e no setor produtivo dos assentamentos.

Com relação ao acesso e à ampliação dos níveis de escolaridade, observou-se que a participação nos cursos do PRONERA possibilitou aos assentados um conjunto de oportunidades que se vincularam à retomada dos estudos, significando uma ampliação dos níveis de escolaridade. As narrativas expressaram marcas importantes da infância dos entrevistados, sendo a ausência e a precariedade do direito à educação recorrentemente mencionada. Eles afirmaram ter estudado na zona rural, sendo muito comum haver escolinhas nas vilas ou nos povoados que ofereciam escolarização da primeira à quarta série, numa mesma sala.

Iniciei com meus sete anos de idade lá na escola da comunidade de Ribeirão Santa Cruz, e que naquela época não tinha até o quarto ano. Era só o primeiro, segundo e terceiro, só. Para concluir o quarto, já tinha que se deslocar para a cidade. E a gente morava a oito quilômetros da sede do município. Chega o momento de dar continuidade, estudando na cidade, me desloquei, saí da casa de meus pais e mudei pra casa do meu irmáo, para estudar. Assim, eu fiz a quarta série, e iniciei a quinta série, mas não concluí (ARMANDO/ MG, 2014)2.

Ao reunir famílias em um único espaço que demandava o exercício dos direitos para sua materialização, pôde-se observar o real sentido e consequência do significado da precariedade educacional e suas relaçóes com as demais dimensôes que garantiam a produção e reprodução da vida. A imposição do padrão de civilizaçáo capitalista se fez no campo rural com o acordo da máquina estatal, ao não reconhecer direitos de populaçôes camponesas por educação contextualizada.

Foi comum observar, nos três Estados, que os assentados vinham de relações de trabalho precarizadas e com alto grau de exploração, na condição de rendeiros, agregados, meeiros, assalariados, dentre outras, que traziam uma história de ausência de oportunidades de escolarização na infância e na adolescência. A questão fundiária não enfrentada pelo sistema político republicano brasileiro requeria um pensar sobre o real no seu sentido histórico e de totalidade, na medida em que poderes econômicos e políticos atuaram e atuam no país para sustentar um padrão civilizatório dominante que tem transformado as terras de uso comum em terras de pastagem e de produção monocultural.

As contradições apontadas nas narrativas se somam aos estudos sobre os desafios da conquista de escolas nos assentamentos nos primeiros anos do PRONERA. Caldart (1999, p. 35) informa que um dos motivos pelos quais o Movimento dos Trabalhadores Rurais Sem Terra (MST) se envolveu com a formação de professores foi a dificuldade para negociar a proposta do movimento com os docentes que trabalhavam nas escolas. Pessoa (1999, p. 82) afirmava que "os 
trabalhadores rurais em luta pela terra descobriram desde o início uma inadequação da escola à sua condição e aos seus projetos".

As narrativas indicaram que os cursos vinculados à educação básica permitiram que um expressivo número de assentados completasse o ciclo obrigatório da educação escolar e que o PRONERA não se limitou a essa oferta. Havia a intencionalidade de fazer avançar o conhecimento e, nesse sentido, a conquista de cursos superiores era estratégica. Mesmo organizados, essa pauta trazia outros desafios para os trabalhadores rurais, na medida em que novos interlocutores eram incorporados no debate político. Essa agenda demandou um longo e intenso processo de negociação e articulação com as instituições de Educação Superior até que conseguissem materializar a oferta da primeira turma de nível superior por meio do curso de formaçáo de educadores do campo.

Foi recorrente nas narrativas a existência de egressos que fizeram sua trajetória escolar, da alfabetização ao superior, nos cursos ofertados com o apoio do PRONERA.

Das turmas de pedagogia, a nossa turma formou 37 educadores. No início do curso todos já tinham vinculação orgânica com os movimentos, com as comunidades do campo, e quando saem do curso, todos já estâo em atividades de coordenação de escola, coordenação de processo - no meu caso, atuando na formação de educadores. Então, o curso dá um salto de qualidade na prática pedagógica, nos vários espaços, desde os formais e os náos formais. Porque o curso de formação de educadores no Paraná, e eu acredito que no espaço onde há esse diálogo entre as comunidades do campo e as instituiçóes de ensino superior, o curso não é uma coisa sozinha (ALEX/PR, 2014).

A trajetória de Alex Verdério, egresso da primeira turma de formação de educadores do Paraná, que hoje é professor na Universidade Federal de Fronteira Sul (UFFS) com atuação acadêmica na área da Educação do Campo, também evidenciou o vínculo e o compromisso dos participantes com as comunidades assentadas e, de forma mais ampla, com as populaçôes campesinas.

Observou-se nas falas dos egressos que a educação foi um instrumento fundamental a permitir a elevação e sua inserção sociopolítica. O PRONERA, ao reconhecer o direito à educação qualificada, possibilitou mudanças nas trajetórias de egressos com inserção profissional nos territórios e, ainda, a compreensão e atuação na construção de processos teórico-metodológicos que questionasse o modelo capitalista como única forma de vida e de produção. Também que compreendessem nas práticas das comunidades tradicionais outras forças sociais que faziam oposição aos requisitos exigidos pela civilização capitalista. 
Eu me senti uma profissional, né? Quando eu terminei o curso, capaz de contribuir, de voltar para os assentamentos e dar um retorno, porque quando eu saí daqui, eu saí com esse compromisso, né? [...] Quando eu concluí o curso, abriu assim uma porta pra mim, de trabalho, porque eu vi que eu ia conseguir um emprego, ia poder ajudar os assentados, né? Com orientação técnica, na área da produção... E aí eu comecei a trabalhar, terminei o curso em 2008. [...] comecei no projeto biodiesel, onde eu trabalhei aqui em oito assentamentos [...]. Para mim, quando eu olho meu diploma de técnica, eu me sinto, assim, muito valorizada, muito bem como profissional, por ter tido essa oportunidade de fazer um curso gratuito, pago pelo PRONERA, que eu jamais na minha família teria condiçóes e que era um sonho da minha família me ver formada. Então, eu me sinto muito realizada profissionalmente (DIOMAR/CE, 2014).

$\mathrm{O}$ acesso à escolaridade permitiu a muito egressos não somente alcançar o Ensino Superior. A oferta de cursos de pós-graduação (especialização e mestrado) garantiu a ampliação de oportunidades de aprofundamento e acesso a chances de trabalho. É importante ressaltar que nas narrativas, os entrevistados relataram a inserção profissional em atividades vinculadas aos assentamentos, no setor de saúde, de educação, produtivo e em outros.

\section{Educação como ato de transformação: escola e setor produtivo}

A partir das narrativas dos egressos que passaram a atuar em escolas, constatou-se o desenvolvimento de práticas que aproximaram a escola da comunidade, o conhecimento científico dos saberes tradicional e a valorização da cultura camponesa em suas diversas formas de expressão. A presença desses educadores nas escolas do campo ou nos centros urbanos contribuiu para se questionar a educação hegemônica realizada nas escolas. $\mathrm{O}$ desenvolvimento de práticas pedagógicas a partir de ensino-aprendizagem interdisciplinar, voltadas para os princípios da Educação do Campo, colaborou para a organização do trabalho pedagógico numa perspectiva emancipadora. Merecem destaque as escolas itinerantes no Estado do Paraná, nas quais atuavam dezenas de egressos dos cursos de Pedagogia da Terra, e o Colégio Estadual Iraci Salete Strozak ${ }^{3}$, considerado uma escola-base e referência nacional para a Educação do Campo.

Práticas que aproximaram a escola da comunidade foram relatadas como atividades que envolviam as famílias e os moradores na sua realização. Narrativas, como a de Jaqueline, revelaram que os educadores buscavam articular teoria e prática para aproximar as escolas da realidade concreta vivenciada pelos assentados, trazendo de forma crítica as contradições na produção do conhecimento acadêmico. 
É uma dificuldade muito grande porque nós temos mania de pensar que a teoria, o conhecimento, é diferente da vida, mas o conhecimento sempre esteve na vida, nós que abstraímos e colocamos na academia e tornou teoria. Então, a gente tem dificuldade muito grande de fazer essa relação. Acho que o momento que pensamos isso é quando conseguimos romper com os muros da escola, e ir pra comunidade, com açóes conjuntas, igual quando nós fomos pensar a cisterna, que nós estávamos com falta de água, nós tivemos um grande trabalho com os professores de matemática, desde como pensar quantos litros são necessários para abastecer a escola, que tamanho, qual a quantidade de litros. Então, são atividades que a gente tenta relacionar com os conteúdos (JAQUELINE/PR, 2014).

O questionamento de práticas já naturalizadas fazia parte da rotina dos educadores do campo. Cenas como a que Vanessa apresentou expressam o olhar de uma docente que percebeu os fios pelos quais transitava a negação dos direitos aos povos campesinos de terem acesso a uma escola que se aproximasse do seu contexto. Com essa atitude, a educadora questionou a invisibilidade da escola do campo no momento da seleção e da distribuição dos livros didáticos, como também pautava o direito dos povos do campo de ocuparem um lugar nas políticas públicas.

Como supervisora, fui convocada para uma reunião que iria escolher materiais e livros didáticos. No dia da reunião eu percebi que foram convocados professores só da área urbana. Questionei: "Por que não é todo mundo junto? Professores da área rural precisam também participar da escolha" (VANESSA/MG, 2014).

A presença dos egressos do PRONERA como educadores nos assentamentos, em Organizaçóes Não Governamentais (ONGs), nas escolas do campo, em espaços de organização política e produtiva tem contribuído para ampliar e fortalecer os princípios, os conceitos e as práticas da Educação do Campo nas áreas reformadas, fazendo avançar o projeto de campo defendido pelos movimentos sociais e sindicais.

Laureci Silva, líder do assentamento no qual militava há 17 anos e que durante a pesquisa exercia o cargo eletivo de vereador, afirmou que foram os cursos do PRONERA a desencadear a formação inicial dos responsáveis na construção de uma das principais cooperativas do assentamento. Ele narrou:

Para vocês terem uma ideia, hoje o presidente da Coperjunho, que tem várias atividades ligadas a muitos programas, é um dos alunos das primeiras turmas que passou por esse processo, então isso pra nós foi estratégico. Esses alunos depois, muitos deles, quando começou a sair os primeiros convênios de assistência técnica do INCRA, já foram pelo convênio, conseguiram pas- 
sar pela qualidade que tiveram nesses cursos. Alguns alunos nós perdemos porque náo ficaram diretamente no assentamento, mas foram aprovados em concurso da EMATER (Empresa de Assistência Técnica e Extensão Rural), que é a empresa pública do estado do Paraná que presta assistência técnica de extensão rural. Alguns estáo na regiáo e de certa forma estão fazendo um trabalho a partir dessa qualificação. E grande maioria deles continua como técnico atuando no assentamento, outros continuaram se qualificando, nós já temos economista hoje formado, aqui trabalhando na Coperjunho, que passaram pelo processo. Outros que estão na universidade. Outros que foram para outras áreas. Então isso foi fundamental. Se nós pegarmos o Assentamento 8 de Junho, claro que não dá pra falar só do 8 de Junho sem falar da regiáo, mas o número de jovens que nós temos na regiâo é muito grande e trabalhando hoje aqui e gerando renda. Se vocês conversarem com eles aqui, eles não têm nenhuma vontade de sair daqui, porque eles não precisam ir para cidade pra ter uma renda mensal, eles têm condições e qualidade de vida a partir do assentamento (LAURECI/PR, 2014).

O processo de múltiplos letramentos e de ampliação da formação escolar em diferentes modalidades oferecidas pelo PRONERA contribuiu ainda com a criação das condiçốes necessárias para a constituição e consolidação da organicidade dos assentamentos. Entende-se por organicidade as formas de organização construídas nos assentamentos que partem de pequenos grupos para discutirem sua realidade e proporem soluçóes para seus problemas, e que numa dinâmica participativa avança para a participação e representação de membros dos grupos em assembleias que se reúnem a cada mês nos assentamentos. Essa forma organizativa também foi relatada por egressos de cursos do PRONERA que aludiam seu aprendizado nos próprios cursos numa dinâmica metodológica a garantir a participaçáo individual e coletiva na tomada de decisóes durante as aulas.

Assim essas práticas participativas foram replicadas nos assentamentos e nas escolas influenciando novas formas organizativas para a criação e gestão de associações e cooperativas; para constituir relaçóes autônomas com os órgãos governamentais e para promover elementos argumentativos para a reivindicação de outras políticas de fortalecimento e territorialização das famílias, de crédito, de aquisição de alimentos, além da participaçáo em cargos públicos e de representação nas instâncias organizativas políticas nos municípios. As narrativas expressaram que o processo de escolaridade propiciou meios de compreensão dos diferentes projetos societários hegemônicos e de construção de espaços de disputa de projetos que confrontavam a propriedade privada, a concentração de terras, de renda, de poder e de conhecimento.

Os cursos, cuja principal característica foi a presença e a participação de trabalhadores e trabalhadoras que lutavam e militavam em movimentos sociais, con- 
tribuíram, a partir dessa presença, para reescrever a história da alienação e dominação a que foram submetidos ao ampliarem espaços de luta e de formação política e ao propiciarem processos de conscientização de sua condição e posição como classe trabalhadora. Aliando a luta política à formação escolar que questionava a posição de classe desses estudantes, observou-se nos depoimentos citados a seguir a elevaçáo da consciência para fomentar o comprometimento com a identidade camponesa.

O curso trouxe muitas contribuiçôes para minha vida, em todas as dimensóes, política, social. Antes deu entrar no curso, não tinha a visão de mundo que hoje eu tenho. Ao longo do curso eu fiz várias reflexôes e eu pude perceber que hoje eu tenho uma visão de mundo mais elevada, mais crítica, que antes eu não tinha. Então, isso foi um grande avanço na minha vida. Às vezes, a gente se sente acomodada por não saber lutar pelos direitos que a gente tem. Quando a gente tem uma visão de mundo mais elevada, uma visão crítica, a gente não se acomoda, não deixa se levar por qualquer comentário, mas vai sempre à luta. O curso me proporcionou isso, ter determinação, lutar sempre, porque quem luta um dia vence (FRANCISCA/CE, 2014).

O depoimento de uma egressa do curso de Jornalismo da Terra também trouxe reflexóes críticas sobre o papel dos meios de comunicação para a alienação da sociedade:

\begin{abstract}
Nossa, eu aprendi muitas coisas: aprendi, com certeza, a ver a sociedade de outra forma [...]. Entáo, aprendi muito que a gente tem que lutar cada vez mais pelos nossos objetivos, principalmente em questáo de estar na universidade, que é muito importante para nós trabalhadores. Sermos é... ter esse conhecimento, a gente tem que deter esse conhecimento da universidade para qualificar mais o nosso trabalho, né? Enquanto militante, nos nossos assentamentos, no MST, então é de fundamental importância. [...] O curso com certeza me proporcionou muito isso, entender melhor como funciona, com certeza, a comunicação em si, nos veículos comunicacionais, né? Porque... aprender a ser mais crítica, né? Porque hoje em dia qualquer notícia que sai, no impresso, no jornal, na TV, sempre fico questionando se é isso, se é aquilo, então a gente teve, a gente conheceu de fato como funciona, né? Por detrás das câmeras, né? Como funcionam os meios de comunicação. Então, isso com certeza eu aprendi muito a ser mais crítica e ter um olhar diferenciado em relação a esse lado da comunicação (LUCILENE/CE, 2014).
\end{abstract}

O fortalecimento da identidade campesina numa perspectiva sociopolítica se fez presente nos depoimentos e nas práticas relatadas pelos depoentes, e se configurou como um elemento para o qual a política do PRONERA colaborou significativamente. 


\section{Contribuições do PRONERA para o fortalecimento da identidade campesina}

O fortalecimento da identidade coletiva foi certamente a repercussão que integrou, deu sentido, ampliou, fortaleceu e criou condiçóes de futuro para as populaçóes campesinas. Vale ressaltar que para os assentados a identidade campesina não se definiu em relação a um espaço físico, mas ao território, aqui compreendido a partir das relaçóes econômicas, políticas, sociais e culturais estabelecidas entre sujeitos em uma determinada configuração societária. Dessa forma, pode-se dizer da identidade socioterritorial como a forma mais adequada para designar as novas formas de produçáo e reprodução da vida que estavam sendo construídas pelos povos assentados. Tratava-se de uma identidade em que um dos aspectos fundamentais para sua estruturação estava na referência a um território, tanto no sentido simbólico quanto concreto. Assim, a identidade territorial se configurava quando o referente simbólico central para a construção dessa identidade partia ou transpassava o território (HAESBAERT, 1999, p. 178).

Passar a compreender que a propriedade sobre os meios de produçáo foi definidora do lugar privilegiado da classe patronal, e que essa condição foi responsável pela exploraçáo da outra classe que vivia do trabalho, trouxe outro e novo processo de entendimento da realidade vivida. A conscientização e a dialogicidade a partir da formação nos cursos potencializaram os sujeitos do campo para a percepção de sua totalidade nos sistemas sociais e sua força como agentes da própria transformação.

A organizaçáo e a participação social ativa foram, portanto, elementos necessários para o enfrentamento das contradiçôes protagonizadas pelo sistema capitalista. Verificou-se nos depoimentos trazidos nas entrevistas o entendimento de que a política do PRONERA, com ênfase na Educação do Campo, foi um meio de resistência à lógica hegemônica de educação a construir novas alternativas para considerar e reafirmar os valores do campo e as relaçóes econômicas e políticas que sustentam as comunidades de base camponesa.

\section{As contradições como elementos de inovação e transformação}

$\mathrm{Na}$ disputa por uma educação transformadora foi necessário tratar das condiçóes estruturais da sociedade e de suas contradiçóes que produzem, determinam e reproduzem a opressão de uma classe sobre outra. Ao mesmo tempo, foi importante pensar a concepção de classe social tratando de suas dimensôes - a econômica e a política - de maneira relacional. Não havia como pensar em mudar as condiçōes materiais de vida do campesinato, que se expressavam historicamente em condições de opressão e de exploração, sem considerar a necessária 
organização política da classe trabalhadora para, em consciência, lutar por novas relaçóes e projeto de sociedade. Nesse sentido, a política do PRONERA trouxe na sua base constitutiva o próprio sentido de contradição.

Contradição significa que as "forças aparentemente opostas" e "presentes ao mesmo tempo em determinada situação, entidade, processo ou evento" (HARVEY, 2016, p. 15) necessitavam ser compreendidas para a sua superação. No momento em que a educação nas suas diferentes modalidades foi colocada como direito por meio das açōes do PRONERA para as populações que conquistaram a Reforma Agrária, essa mesma educação foi problematizada nas escolas e nas universidades para atender aos interesses da classe camponesa e náo aos da classe patronal. Ou seja, a contradição se colocou de forma visível para se tornar, como sugere Marx, uma possibilidade fecunda para o fortalecimento da formaçáo para o projeto de sociedade defendido pelo campesinato e não para a formação de mão de obra para o mundo do trabalho capitalista.

Essa foi uma das contradiçóes trazidas para a educação a ser conduzida nas práticas educativas do PRONERA: Quem formar e para quê? A categoria de trabalho foi então acessada como um elo na escola. Assim a própria contradiçâo esclarecida trouxe à tona e se colocou no seu movimento de transformação da sociedade. Afinal, a contradição vai sempre existir nas sociedades, esse é um de seus princípios. Porém, atuar diante das contradiçôes foi e será papel dos movimentos sociais, como lembrou a narrativa a seguir:

As escolas contribuem para essa memória da luta, nós temos que firmar isso com a participação na luta, porque a luta não morreu, a luta continua. A luta não para. Uma grande preocupação nossa é a condição da juventude e principalmente quando se trata da história da renda. Hoje é muito comum a preocupação que os filhos tenham um emprego. Então, muitos pais não estão preocupados com a permanência do jovem. Estáo preocupados que esse jovem tenha um emprego e que ajude eles a partir desse emprego. Isso é um problema para nós, os pais pensando em emprego pressionando o jovem. Nós estamos pensando na reprodução camponesa, na continuidade daquele assentamento, entâo entre esses dois interesses é como a gente constrói uma estratégia (MARIA DE JESUS/CE, 2014).

A escola foi assim um campo de lutas, de disputas para a construção de uma sociedade a defender os interesses de determinada classe. Estando a escola situada em assentamentos, comunidades rurais e voltada para populaçóes de origem camponesa, indígena e negra, a contradição deve se colocar para que compreendam as próprias experiências de exploração e de opressão no mundo e no trabalho de base capitalista. Significa partir da realidade vivida, das condiçóes estruturais 
que regem a sociedade capitalista para, em contrapartida, dar centralidade aos significados de ser camponês, agricultor, trabalhador rural.

Assim é que a educação foi e é um campo de disputa para fazer valer a dinâmica econômica e política que interessa aos camponeses, indígenas e quilombolas. Estudar náo deve ser uma ferramenta para sair do campo, e sim para fortalecer esses territórios de vida e de produção camponesa.

Conhecer a sua condição de classe trabalhadora em relação aos meios de produção, aos modos de produção e às relações de trabalho naquilo que se denomina de dinâmicas econômicas deve ser um processo que ocorre articulado à dinâmica política que conduz as forças produtivas e define as ações de poder hegemônico na sociedade. Nessa direção, os egressos dos cursos se inseriram nas escolas do campo como educadores para desvelar aquilo que Marx denominou de "fetichismo", ou seja, "as várias máscaras, disfarces e distorçóes do que realmente acontece ao nosso redor" (HARVEY, 2016, p. 18) e para desvendar as contradições que estavam no intermédio entre a realidade e a aparência "no mundo em que vivemos" (HARVEY, 2016, p. 17). É, portanto, com base no desvelamento das contradiçôes que a dimensão do trabalho camponês adquiriu importância e protagonizou a formaçáo nas escolas do campo e a formação de assentados no campo de atuação do PRONERA.

Pensar a escola como lugar de identificação das contradições que movem a sociedade capitalista foi também espaço de enfrentamento, criação e transformação da realidade. Assim foi que os egressos inseriram na escola novas abstraçôes, como o entendimento de que a agricultura camponesa poderia ser autônoma e responsável pelos diferentes subsistemas que regulavam o sistema agroalimentar da agricultura familiar. Nessa direção, passaram a trabalhar nas escolas com a formação para atuação na agroindústria, para incentivar a integração da produção em circuitos curtos de comercialização.

Por fim e segundo os participantes da pesquisa beneficiários das açóes do PRONERA, este contribuiu para:

- minimizar os altos índices de analfabetismo;

- qualificar pedagógica e tecnicamente seus educandos e educadores;

- propagar as possibilidades de práticas produtivas e tecnológicas menos impactantes à natureza e a toda forma de vida no planeta;

- formar professores que respeitassem a cultura e a identidade da população rural, assim como a noção de campo como espaço de vida;

- desenvolver a cooperação e o fortalecimento da solidariedade orgânica, das práticas comunitárias, da valorização da agricultura familiar e camponesa, entre outras necessidades existentes entre as famílias para o enfrentamento de seus antagonistas como o agronegócio. 


\section{Notas}

1. A pesquisa de caráter qualitativo foi realizada nos Estados da Paraíba, Maranhão, Ceará, Pará, Mato Grosso do Sul, Minas Gerais e Paraná. Integrou a II PNERA, que levantou dados quantitativos e qualitativos das açôes do PRONERA no período de 1998 a 2011.

2. A identificaçáo dos entrevistados foi realizada com os nomes indicados pelos mesmos.

3. O Colégio Iraci Salete Strozak fica no Assentamento Marcos Freire, no município de Rio Bonito do Iguaçu, Paraná. Seu nome foi escolhido em homenagem a Iraci Salete Strozak, que faleceu em 21 de setembro de 1997 em um acidente de ônibus, aos 27 anos. Era uma líder da comunidade, a primeira mulher a coordenar uma regional do MST (coordenadora da Regional do Norte Velho).

\section{Referências}

ANTUNES-ROCHA, M.I.; MOLINA, M.C. Educação do campo: história, práticas e desafios no âmbito das políticas de formação de educadores - reflexóes sobre o PRONERA e o PROCAMPO. Reflexão e Ação, Santa Cruz do Sul, v. 22, n. 2, p. 220253, jul./dez. 2014. Disponível em: $\leq$ https://online.unisc.br/seer/index.php/reflex/article/ viewFile/5252/3689>. Acesso em: 29 ago. 2017.

CALDART, R.S. Projeto popular e escolas do campo. Brasília: Articulação Nacional por uma Educação Básica do Campo, 1999.

ESMERALDO, G.G.S.L.; AZEVEDO, H.S.; CASIMIRO FILHO, F.; MOREIRA, M.L.S. Programa Residência Agrária Nordeste I: a força de uma experiência. In: MOLINA, M.C.; ESMERALDO, G.G.S.L.; NEUMANN, P.S.; BERGAMASCO, S.M.P.P. Educação do campo e formação profissional: a experiência do Programa Residência Agrária. Brasília: MDA, 2009. p. 63-84.

HAESBAERT, R. Identidades territoriais. In: ROSENDAHL, Z.; CORREA, R.L. (Orgs.). Manifestaçôes da cultura no espaço. Rio de Janeiro: EdUERJ, 1999.

HARVEY, D. 17 contradiçóes e o fim do capitalismo. São Paulo: Boitempo, 2016.

IANNI, O. (Org.). Marx: Sociologia. São Paulo: Ática, 1987.

INSTITUTO DE PESQUISA ECONÔMICA APLICADA - IPEA. II Pesquisa Nacional sobre Educação na Reforma Agrária: avaliação de açóes no Maranhão. Rio de Janeiro, 2016a. Disponível em <https:/www.ipea.gov.br/portal/images/stories/ PDFs/relatoriopesquisa/160902 relatorio pnera maranhao.pdf $>$. Acesso em: 30 jul. 2017.

II Pesquisa Nacional sobre Educação na Reforma Agrária: uma análise sobre o estado da Paraíba (1998-2011). Rio de Janeiro, 2016b. Disponível em: <https://www.ipea. gov.br/portal/images/stories/PDFs/relatoriopesquisa/160725 relatorio pnera paraiba. pdf $>$. Acesso em: 30 jul. 2017. 
INSTITUTO DE PESQUISA ECONÔMICA APLICADA - IPEA. II Pesquisa Nacional sobre Educação na Reforma Agrária: uma análise sobre o estado de Mato Grosso do Sul (1998-2011). Rio de Janeiro, 2016c. Disponível em: <http://www.ipea.gov.br/ portal/images/stories/PDFs/relatoriopesquisa/relatorio pnera-matogrossodosul.pdf $>$. Acesso em: 30 jul. 2017.

. II Pesquisa Nacional de Educação em Áreas de Reforma Agrária: repercussôes no Estado de Minas Gerais. Rio de Janeiro, 2016d. Disponível em: <http://www.ipea.gov.br/portal/ index.php?option=com_content\&view=article\&id=28543>. Acesso em: 29 mar. 2017.

. II Pesquisa Nacional de Educação em Áreas de Reforma Agrária: repercussóes no Estado do Ceará. Rio de Janeiro, 2016e. Disponível em: <http://repositorio.ipea.gov.br/ handle/11058/7463>. Acesso em: 29 mar. 2017.

. II Pesquisa Nacional sobre Educação na Reforma Agrária: repercussóes no estado do Pará (regiōes sul e sudeste). Rio de Janeiro, 2016f. Disponível em: $\leq$ https://www.ipea.gov. $\mathrm{br} /$ portal/images/stories/PDFs/relatoriopesquisa/relatorio pnera sul sudeste web.pdf $>$. Acesso em: 30 jul. 2017.

- II Pesquisa Nacional de Educação em Áreas de Reforma Agrária: repercussóes no Estado do Paraná. Rio de Janeiro, 2016g. Disponível em: <http://repositorio.ipea.gov. br/bitstream/11058/7417/1/RP II\%20Pesquisa\%20-\%20Paran\%C3\%A1 2016.pdf >. Acesso em: 29 ago. 2017.

. II PNERA: Relatório da II Pesquisa Nacional sobre a Educação na Reforma Agrária. Rio de Janeiro, 2015. Disponível em: <http://www.ipea.gov.br/portal/images/ stories/PDFs/relatoriopesquisa/150618_relatorio_ii_pesquisa\%20nacional.pdf $>$. Acesso em: 29 mar. 2017.

O Programa Nacional de Educação na Reforma Agrária: entre experiências vividas e análises científicas. Rio de Janeiro, 2016h. Disponível em: <http://www.ipea.gov.br/ portal/images/stories/PDFs/relatoriopesquisa/160630 relatorio o-programa-nacional. pdf>. Acesso em: 30 jul. 2017.

MOLINA, M.C. O PRONERA como construção prática e teórica da Educação do Campo. In: ANDRADE, M.R.; DI PIERRO, M.C., MOLINA, M.C.; JESUS, S.M.A. de (Org.). Educação na Reforma Agrária em perspectiva. São Paulo: Ação Educativa; Brasília: Pronera, 2004.

PESSOA, J. de M. A revanche camponesa. Goiânia: Editora da UFG, 1999.

Recebido em 24 de maio de 2017.

Aprovado em 15 de agosto de 2017. 